\title{
Association of polymorphisms in the Tau and Saitohin genes with Parkinson's disease
}

\author{
C Levecque, A Elbaz, J Clavel, J S Vidal, P Amouyel, A Alpérovitch, C Tzourio, M C Chartier-Harlin
}

J Neurol Neurosurg Psychiatry 2004;75:478-480. doi: 10.1136/jnnp.2003.015750

\begin{abstract}
Background: The Saitohin gene has recently been identified in intron 9 of the Tau gene. Because an association between Parkinson's disease and Tau has been described, Saitohin represents a candidate gene for Parkinson's disease.

Objective: To test these two genes for their association with Parkinson's disease in a large community based case-control study.

Results: Cases ( $n=208$ ) were more often homozygotes for the Tau $\mathrm{HI}$ haplotype than controls ( $\mathrm{n}=483$; odds ratio $(O R)=1.71$ (95\% confidence interval, 1.20 to 2.43$)$; $\mathrm{p}=0.003$ ), and the saitohin $Q$ allele was in complete linkage disequilibrium with the $\mathrm{H} 1$ haplotype. This association was stronger among cases with Parkinson's disease onset below 65 years ( $\leqslant 65$ years: $O R=2.52$ ( 1.49 to 4.25$) ; p<0.001$ ) than among those with older onset $(>65$ years: $O R=1.20$ (0.73 to 1.98); $\mathrm{p}<0.47$ ).

Conclusions: The data suggest that there is a functional polymorphism at this locus involved in Parkinson's disease.
\end{abstract}

$\mathrm{S}$ everal polymorphisms scattered through the Tau gene have been associated with tauopathies sharing motor symptoms with Parkinson's disease. ${ }^{12}$ Moreover, mutations have been identified indicating that tau dysfunction is sufficient to cause these disorders. ${ }^{13}{ }^{4}$ Interestingly, several studies have also found an association between the Tau gene and Parkinson's disease..$^{5-10}$

A gene called Saitohin was recently described in intron 9 of the Tau gene. ${ }^{11}$ Despite the association observed between Tau and Parkinson's disease, tau aggregates are rarely observed in brains from affected patients. Thus a gene near the Tau gene may explain the association. This hypothesis has not been tested yet, so we examined the association between the Tau gene and Parkinson's disease in a community based study, and evaluated the implication of the Saitohin gene.

\section{METHODS}

Participants were recruited through a French health insurance organisation, the Mutualité Sociale Agricole (MSA), which is responsible for the reimbursement of health related expenses to workers connected with agriculture. The study has been described in detail previously. ${ }^{12}{ }^{13}$ Cases of Parkinson's disease were recruited from among subjects submitting their first application for benefit from the free health care coverage for Parkinson's disease. The diagnosis of Parkinson's disease was established using standard criteria after examination by a neurologist or, when such an examination was not possible, using information provided by the patient's neurologist. ${ }^{12-14}$ Controls were recruited among MSA affiliates. A maximum of three controls were matched with each case for age ( \pm 2 years), sex, and region of residency at the time of the study.
Participants provided information on a family history of Parkinson's disease among first degree relatives and on the country of birth of their parents. Information on smoking was obtained through a face to face questionnaire. Information on pesticide exposure was obtained using a two stage, case by case exposure assessment procedure. ${ }^{12}{ }^{13}$ Subjects were classified as ever or never smokers and as ever or never pesticide users (for gardening or professional use) before the onset of Parkinson's disease (in cases) or before the index date in controls (the index date is the date of onset in the matched case).

The ethics committee of the Hôpital du Kremlin-Bicêtre approved the research protocol, and all subjects signed their informed consent.

Three exonic polymorphisms were genotyped in exons 3, 9 (variation 9iii), and 13 of the Tau gene. ${ }^{2}$ The Tau haplotypes were constructed as reported previously. ${ }^{2}$ The A/G polymorphism in Saitohin was genotyped as described. ${ }^{11}$ Sequencing of the coding region of the Saitohin gene was done using the primers 5'-CCCTGTAAACTCTGACCACAC-3' and 5'-GCCACTTTTCCACACTTCGT-3'.

\section{Statistics}

Odds ratios (OR) and 95\% confidence intervals (CI) were calculated using conditional logistic regression. Analyses were based on subjects with both parents of European origin to reduce the risk of population stratification bias; we also carried out analyses restricted to subjects with both parents born in France. Analyses of the interaction between Tau polymorphisms and other variables were undertaken by estimating individual and joint effects of the variables and by introducing multiplicative terms in the models.

\section{RESULTS}

Cases $(n=208)$ and controls $(n=483)$ had a mean (SD) age of 67 (7) years. The mean age at Parkinson's disease onset was 63 (7) years. Most of the cases (91\%) were sporadic. The parents of $92 \%$ of cases and $93 \%$ of controls were born in France. Twenty five per cent of cases and 33\% of controls were ever-smokers; $71 \%$ of cases and $68 \%$ of controls had been pesticide users. ${ }^{13}$

Tau haplotypes were constructed and their frequencies calculated (table 1). Polymorphisms in exon 3 and 13 of Tau are in complete linkage disequilibrium, and the polymorphism in exon 9 only occurs on the Hl haplotype. There were no differences in this polymorphism's frequency between cases and controls $(p=0.59)$; we therefore pooled carriers of the exon 9 polymorphism with the $\mathrm{Hl}$ group.

$\mathrm{Hl} \mid \mathrm{Hl}$ homozygotes had a greater risk of Parkinson's disease than $\mathrm{H} 1 \mid \mathrm{H} 2$ and $\mathrm{H} 2 \mid \mathrm{H} 2$ carriers (table 1). Similar findings were observed in analyses restricted to subjects with French parents $(\mathrm{OR}=1.68(95 \% \mathrm{CI}, 1.14$ to 2.47$) ; \mathrm{p}=0.008)$, or without a family history of Parkinson's disease (OR $=1.68$ ( 1.15 to 2.45); $\mathrm{p}=0.007$ ). An interaction between the $\mathrm{Hl}$ haplotype and age at Parkinson's disease onset was observed. 
Table 1 Association between Parkinson's disease and the $\mathrm{H} 1$ haplotype in the Tau gene

\begin{tabular}{|c|c|c|c|c|c|c|}
\hline & $\mathbf{n}$ & $\mathrm{H} 1 \mid \mathrm{H} 1 \%$ (n) & $\mathrm{H} 1 \mid \mathrm{H} 2 \%$ (n) & $\mathrm{H} 2 \mid \mathrm{H} 2 \%(\mathrm{n})$ & $\begin{array}{l}\text { OR }(95 \% \mathrm{Cl}) \mathrm{H} 1|\mathrm{H} 1 v \mathrm{H} 1| \mathrm{H} 2+ \\
\mathrm{H} 2 \mid \mathrm{H} 2\end{array}$ & p Value \\
\hline \multicolumn{7}{|l|}{ Overallt } \\
\hline Controls & 483 & $52.4(253)$ & $41.0(198)$ & $6.6(32) \S$ & & \\
\hline Cases & 208 & $64.4(134)$ & $31.3(65)$ & $4.3(9)$ & 1.71 (1.20 to 2.43 ) & 0.003 \\
\hline \multicolumn{7}{|l|}{ Men } \\
\hline Controls & 284 & $51.8(147)$ & $42.9(122)$ & $5.3(15)$ & & \\
\hline Cases & 118 & $65.3(77)$ & $30.5(36)$ & $4.2(5)$ & 1.86 (1.15 to 2.99$)$ & 0.01 \\
\hline \multicolumn{7}{|l|}{ Women } \\
\hline Controls & 199 & $53.3(106)$ & $38.2(76)$ & $8.5(17)$ & & \\
\hline Cases & 90 & $63.3(57)$ & $32.2(29)$ & $4.5(4)$ & $1.54(0.91$ to 2.63$)$ & 0.11 \\
\hline \multicolumn{7}{|c|}{ Onset $\leqslant 65$ years* } \\
\hline Controls & 264 & $53.4(141)$ & $39.4(104)$ & 7.2 (19) & & \\
\hline Cases & 116 & $72.4(84)$ & $27.6(32)$ & - & $2.52(1.49$ to 4.25$) \mp$ & $<0.001$ \\
\hline \multicolumn{7}{|c|}{ Onset $>65$ years* } \\
\hline Controls & 219 & $51.2(112)$ & $42.9(94)$ & $5.9(13)$ & & \\
\hline Cases & 92 & $54.3(50)$ & $35.9(33)$ & $9.8(9)$ & 1.20 (0.73 to 1.98$) \ddagger$ & 0.47 \\
\hline \multicolumn{7}{|c|}{$\begin{array}{l}\text { *Median age at onset. } \\
+24 \mathrm{H} 1 \mid \mathrm{H} 1 \text { controls and } 19 \mathrm{H} 1 \mid \mathrm{H} 1 \text { cases carried the exon } 9 \text { polymorphism on one } \\
9 \text { polymorphism on the } \mathrm{H} 1 \text { haplotype. No } \mathrm{H} 2 \mid \mathrm{H} 2 \text { cases or controls carried the exo } \\
\text { flnteraction between } \mathrm{H} 1 \mid \mathrm{H} 1 \text { and age at onset, } \mathrm{p}=0.05 \text {. } \\
\text { §Tau haplotypes were in Hardy-Weinberg equilibrium among controls }(\mathrm{p}=0.66) \text {. } \\
\text { 9 Interaction between } \mathrm{H} 1 \mid \mathrm{Hl} \text { and sex was not significant. }\end{array}$} \\
\hline
\end{tabular}

The association between the Tau gene and Parkinson's disease was stronger among cases with onset under 65 years (median age at onset) than among patients with later onset. Moreover, in analyses restricted to cases, the frequency of $\mathrm{Hl}$ homozygotes was higher among younger than among older patients $(72.4 \% \quad v$ 54.3\%; $\mathrm{p}=0.007)$, while there was no difference among controls (table 1).

Saitohin polymorphism showed the same frequencies as the $\mathrm{Hl}$ haplotype (controls: $\mathrm{AA}=52.4 \%, \mathrm{AG}=41.0 \%$, GG $=6.6 \%$; cases: $\mathrm{AA}=64.4 \%, \mathrm{AG}=31.3 \%, \mathrm{GG}=4.3 \%)$; thus the A allele was in complete linkage disequilibrium with the $\mathrm{Hl}$ haplotype (fig 1). Sequencing of the Saitohin gene in 15 patients $(10 \mathrm{Hl}|\mathrm{H} 1,5 \mathrm{H} 2| \mathrm{H} 2)$ failed to detect any other nucleotide variations.

We found no interaction between the Hl haplotype and pesticide exposure or cigarette smoking. In multivariate analyses, adjusting for these two variables did not modify our findings $(\mathrm{OR}=1.72(1.20$ to 2.50$) ; \mathrm{p}=0.004)$.

\section{DISCUSSION}

In this large community based study, we observed a higher proportion of $\mathrm{Hl}$ homozygotes for the Tau gene in Parkinson's disease patients than in controls, and showed that the A/G polymorphism in the Saitohin gene was in complete linkage disequilibrium with the HI haplotype.

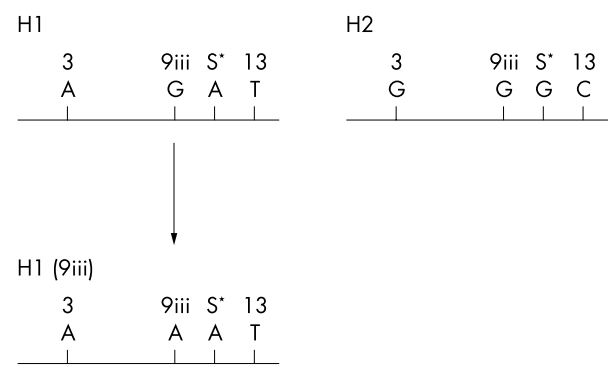

Figure 1 Schematic representation of Tau and Saitohin haplotypes. Polymorphism 9iii is only present on the more common $\mathrm{Hl}$ haplotype, and leads to the H1 (9iii) haplotype. $S^{*}$, saitohin; the A to G substitution changes the amino acid from a glutamine $(Q)$ to an arginine $(R)$.
As genetic susceptibility is hypothesised to play a greater role in patients with a younger onset of Parkinson's disease, ${ }^{15}{ }^{16}$ we analysed the implication of the Tau haplotype according to age at onset. We observed a significantly stronger association among Parkinson's disease patients with onset below median age than among patients with an older onset. In addition, in case-only analysis, $\mathrm{Hl} \mid \mathrm{Hl}$ carriers were significantly more common among patients with a younger disease onset. This finding is in agreement with a previous study in which the frequency of $\mathrm{Hl}$ homozygotes among cases with an age at examination (which is correlated with the age at onset) before 71 years was higher than among older patients, although the difference did not reach significance. $^{8}$

An association between the Tau gene and Parkinson's disease has been found in several studies, but not all. It has been hypothesised that in some studies the association may have occurred because they included patients with progressive supranuclear palsy (PSP) misdiagnosed as Parkinson's disease. It is important to note that our study was community based. Thus the frequency of other causes of parkinsonism misdiagnosed as Parkinson's disease is likely to be lower than in previous studies that were hospital based (where atypical cases are found more often). A correction for potential diagnostic misclassification has been carried out in several studies. We did a similar correction by assuming that $6 \%$ $(n=12)$ of the cases had PSP, with $88.7 \%$ of them being $\mathrm{Hl} \mid \mathrm{Hl} .^{8}$ After excluding these cases and their matched controls at random, the odds ratio remained significantly greater than $1(\mathrm{OR}=1.60$ ( 1.11 to 2.20$), \mathrm{p}=0.01)$. Finally, some studies were underpowered to detect an odds ratio of 1.70 with $80 \%$ power.

As Tau and Saitohin polymorphisms are in linkage disequilibrium and both are associated with Parkinson's disease, our data confirm that there may be genetic susceptibility factors at this locus. This hypothesis is in agreement with the results of a complete genome screen among 174 families with idiopathic Parkinson's disease (mean age at onset, 60 (13) years) which detected significant evidence for linkage on chromosome 17q, about $8 \mathrm{cM}$ from the Tau gene. ${ }^{17}$ 
Several observations support the potential involvement of Saitohin or Tau in the development of Parkinson's disease. On the one hand, associations between the $\mathrm{Hl}$ haplotype in the Tau gene and PSP, FTDP-17, or Parkinson's disease have been shown. ${ }^{125}$ 7-10 In FTDP-17, most of the mutations located in or around exon 10 affect the splicing regulatory element structure and lead to an increased ratio of four repeat to three repeat tau isoforms. ${ }^{18}{ }^{19}$ Exon 10 and/or downstream intronic sequences also contain a complex array of enhancer or inhibitor cis-acting elements that modulate the use of a weak $5^{\prime}$ splice site. ${ }^{20}$ FTDP-17, PSP, and Parkinson's disease are all characterised by parkinsonian symptoms. The association of FTDP-17 and PSP with the HI haplotype may be explained by the role of tau in these disorders, but tau is not a major component of Lewy bodies, and no neurofibrillary tangles are usually observed in Parkinson's disease. However, it has been shown that $\alpha$-synuclein can bind to tau and stimulate tau phosphorylation. ${ }^{21}$ Furthermore, the overexpression of transgenic Tau in Drosophila results in neuronal death without formation of inclusions. ${ }^{22}$ Thus Tau overexpression may be sufficient to cause neuronal death, without the need for the formation of fibrillar aggregates.

On the other hand, Saitohin appears as an interesting candidate gene for Parkinson's disease because of its gene localisation and brain expression. Both genes could share some regulatory elements. Indeed there is an overlap in their tissue expression distribution, including that in the brain. Regulatory elements (CpG islands) are associated with exon 1 of Tau gene, and also exon 9 near the Saitohin gene, suggesting the importance of this region in regulating transcription of tau or saitohin. ${ }^{23}$ In order to identify a potential mutation explaining the observed association, we sequenced the coding region of the Saitohin gene in 15 patients but we did not detect other variations. However, we cannot exclude the presence of polymorphisms in the regulatory regions of the Saitohin gene, or a change in methylation in the CpG islands around exons 1 and 9.

Our data do not allow us to discriminate between Saitohin and Tau genes. Additional work is therefore needed before we can fully understand the associations observed at this locus with the development of Parkinson's disease, and implicate one of these two genes or another nearby. It would be of interest to sequence the entire gene of this locus and to search for the presence of saitohin in Lewy bodies.

\section{ACKNOWLEDGEMENTS}

We thank all the MSA (Mutualité Sociale Agricole) physicians who interviewed the participants and the MSA employees who helped with the coordination of the study. Drs David Gervais and Lamia Benslamia participated in the examination of Parkinson's disease patients. Mrs Chantal Cordelier and Drs Carline Amiel, Frédérique Brunner, and Jean-Philippe Galanaud helped with the assessment of exposure to pesticides. Dr Safia Zenagui participated in the coordination of the study. We thank Prakash Rucktooa, Aurélie Melchior, Xavier Hermant, and Vincent Mouroux for their technical assistance. The study was supported by the INSERM, the Institut Pasteur de Lille, the MSA, and the French Ministry of the Environment. CL is a recipient of the Ministère de la Recherche et de la Technologie.

\section{Authors' affiliations}

C Levecque, P Amouyel, M C Chartier-Harlin, INSERM Unit 508, Institut Pasteur de Lille, Lille, France

A Elbaz, A Alpérovitch, C Tzourio, INSERM Unit 360, Hôpital de la Salpêtrière, Paris, France
J Clavel, INSERM Unit 170, 16 Avenue Paul Vaillant-Couturier, Villejuif, France

J S Vidal, Service de Neurologie, Hôpital Saint-Antoine, Paris, France Competing interests: none declared

Correspondence to: $\operatorname{Dr} M$ C Chartier-Harlin, INSERM Unit 508 Institut Pasteur de Lille, 1, rue du Pr Calmette, BP 245, 59019 Lille Cedex,

France; marie-christine.chartier@pasteur-lille.fr

Received 31 March 2003

In revised form 11 July 2003

Accepted 11 July 2003

\section{REFERENCES}

1 Verpillat $\mathbf{P}$, Camuzat A, Hannequin D, et al. Association between the extended tau haplotype and frontotemporal dementia. Arch Neurol 2002;59:935-9.

2 Baker M, Litvan I, Houlden $\mathrm{H}$, et al. Association of an extended haplotype in the tau gene with progressive supranuclear palsy. Hum Mol Genet 1999;8:711-15.

3 Conrad C, Andreadis A, Trojanowski JQ, et al. Genetic evidence for the involvement of tau in progressive supranuclear palsy. Ann Neurol 1997; 41:277-81

4 Poorkaj P, Muma NA, Zhukareva V, et al. An R5L tau mutation in a subject with a progressive supranuclear palsy phenotype. Ann Neurol 2002;52:511-16.

5 Pastor $P$, Ezquerra M, Munoz E, et al. Significant association between the tau gene A0/A0 genotype and Parkinson's disease. Ann Neurol 2000;47:242-5.

6 Golbe LI, Lazzarini AM, Spychala JR, et al. The tau A0 allele in Parkinson's disease. Mov Disord 2001; 16:442-7.

7 Hoenicka J, Perez M, Perez-Tur J, et al. The tau gene AO allele and progressive supranuclear palsy. Neurology 1999;53:1219-25.

8 Maraganore DM, Hernandez DG, Singleton AB, et al. Case-control study of the extended tau gene haplotype in Parkinson's disease. Ann Neurol 2001;50:658-61

9 Martin ER, Scott WK, Nance MA, et al. Association of single-nucleotide polymorphisms of the tau gene with late-onset Parkinson disease. JAMA $2001 ; 286: 2245-50$.

10 Farrer M, Skipper L, Berg $M$, et al. The tau $\mathrm{H} 1$ haplotype is associated with Parkinson's disease in the Norwegian population. Neurosci Lett 2002;322:83-6.

11 Conrad C, Vianna C, Freeman M, et al. A polymorphic gene nested within an intron of the tau gene: implications for Alzheimer's disease. Proc Natl Acad Sci USA 2002;99:7751-6.

12 Elbaz A, Levecque C, Clavel J, et al. S18Y polymorphism in the UCH-L1 gene and Parkinson's disease: evidence for an age-dependent relationship. Mov Disord 2003;18:130-7

13 Levecque C, Elbaz A, Clavel J, et al. Association between Parkinson's disease and polymorphisms in the $\mathrm{nNOS}$ and iNOS genes in a community-based case-control study. Hum Mol Genet 2003;12:79-86.

14 de Rijk MC, Rocca WA, Anderson DW, et al. A population perspective on diagnostic criteria for Parkinson's disease. Neurology 1997;48:1277-81.

15 Elbaz A, Grigoletto F, Baldereschi M, et al. Familial aggregation of Parkinson's disease: a population-based case-control study in Europe. EUROPARKINSON Study Group. Neurology 1999;52:1876-82.

16 Payami H, Zareparsi S, James D, et al. Familial aggregation of Parkinson disease: a comparative study of early-onset and late-onset disease. Arch Neurol 2002;59:848-50.

17 Scott WK, Nance MA, Watts RL, et al. Complete genomic screen in Parkinson disease: evidence for multiple genes. JAMA 2001;286:2239-44.

18 Varani L, Hasegawa M, Spillantini MG, et al. Structure of tau exon 10 splicing regulatory element RNA and destabilization by mutations of frontotemporal dementia and parkinsonism linked to chromosome 17. Proc Natl Acad Sci USA 1999;96:8229-34.

19 Grover A, Houlden H, Baker M, et al. 5' splice site mutations in tau associated with the inherited dementia FTDP-17 affect a stem-loop structure that regulates alternative splicing of exon 10. J Biol Chem 1999;274:15134-43.

20 D'Souza I, Schellenberg GD. Tau Exon 10 expression involves a bipartite intron 10 regulatory sequence and weak $5^{\prime}$ and $3^{\prime}$ splice sites. J Biol Chem 2002;277(29):26587-99.

21 Jensen PH, Hager H, Nielsen MS, et al. Alpha-synuclein binds to Tau and stimulates the protein kinase A-catalyzed tau phosphorylation of serine residues 262 and 356. J Biol Chem 1999:274:25481-9.

22 Wittmann CW, Wszolek MF, Shulman JM, et al. Tauopathy in Drosophila: neurodegeneration without neurofibrillary tangles. Science 2001;293:711-14

23 Andreadis A, Brown WM, Kosik KS. Structure and novel exons of the human tau gene. Biochemistry 1992;31:10626-33. 